\title{
Existence of Different Subtypes of Nicotinic Acetylcholine Receptors in the Rat Habenulo-interpeduncular System
}

\author{
Christophe Mulle, Catherine Vidal, Pierre Benoit, and Jean-Pierre Changeux \\ UA CNRS D1284 "Neurobiologie Moléculaire," Département des Biotechnologies, Institut Pasteur, 75724 Paris Cedex 15, \\ France
}

Neuronal nicotinic ACh receptors (nAChRs) are present in the rat medial habenula (MHB) and interpeduncular nucleus (IPN), two brain regions connected through the fasciculus retroflexus (FR). The goal of the present study was to compare the electrophysiological and pharmacological characteristics of nAChRs located at pre- and postsynaptic sites within the MHB-IPN system. nAChRs located on the soma of IPN neurons were studied using patch-clamp techniques and a preparation of acutely isolated neurons. Whole-cell currents evoked by Ach and nicotine showed an intense rectification at positive membrane potentials. nAChR channels were relatively nonselective for cations, had a unitary conductance of $35 \mathrm{pS}$, and were activated by several nicotinic agonists with the following rank order: cytisine $>A C h$ $>$ nicotine $>$ dimethylphenylpiperazinium (DMPP). They were blocked by mecamylamine, hexamethonium, curare, and dihydro- $\beta$-erythroidine (DHBE), but were insensitive to $\alpha$-bungarotoxin and neuronal bungarotoxin. In contrast, nAChRs recorded on the soma of MHB neurons under equivalent experimental conditions exhibited different characteristics for single-channel conductance and agonist and antagonist sensitivity. The pharmacological properties of presynaptic nAChRs in the IPN were analyzed in a rat brain slice preparation. Stimulation of the FR produced a presynaptic afferent volley recorded in the rostral subnucleus of the IPN. Nicotinic agonists decreased the amplitude of the afferent volley with different efficacies: nicotine > cytisine $>$ ACh > DMPP. The action of nicotine was insensitive to $\alpha$-bungarotoxin and to neuronal bungarotoxin, but was blocked by mecamylamine, hexamethonium, curare, and DHBE, with $I_{50}$ values different from those reported for IPN postsynaptic nAChRs. This study thus demonstrates the functional diversity of nAChRs in the rat CNS.

Recent studies of cloned nucleic acid sequences have demonstrated the existence of a family of genes that encode functional nicotinic ACh receptors (nAChRs) found on muscle and nerve cells (for review, see Lindstrom et al., 1987; see also Deneris et al., 1988, 1989; Nef et al., 1988; Wada et al., 1988; Duvoisin

\footnotetext{
Received Jan. 7, 1991; revised Mar. 25, 1991; accepted Mar. 27, 1991.

This work was supported by grants from the College de France, the Centre National de la Recherche Scientifique, and the Ministere de la Recherche and by Institut National de la Santé et de la Recherche Médicale Contract 872004 and Direction des Recherches Etudes et Techniques Contract 87/211.

Correspondence should be addressed to Christophe Mulle, Laboratoire de Neurobiologie Moléculaire, Département des Biotechnologies, Institut Pasteur, 25 rue du Dr. Roux, 75724 Paris Cedex 15, France.

Copyright (C) 1991 Society for Neuroscience $0270-6474 / 91 / 112588-10 \$ 03.00 / 0$
}

et al., 1989; Boulter et al., 1990). The genes encoding neuronal nAChR subunits have been divided into two categories: (1) subunits named $\alpha$-subunits because of homologies with muscle $\alpha$-subunits $\left(\alpha_{2}-\alpha_{6}\right.$ in the rat brain and $\alpha_{2}-\alpha_{7}$ in the chicken brain) and (2) subunits referred to as $\beta$-subunits $\left(\beta_{2}-\beta_{5}\right)$ in the rat brain or non- $\alpha$-subunits in the chicken brain (non- $\alpha_{1}$ to non- $\alpha_{3}$ ). Expression studies with Xenopus oocytes injected with either cDNAs or mRNAs have shown that various paired combinations of $\alpha$ and $\beta$ - (or non- $\alpha-$ ) subunits can form functional nAChRs with distinct pharmacological and electrophysiological properties (Ballivet et al., 1988; Bertrand et al., 1990; Luetje et al., 1990; Papke et al., 1989a,b). Furthermore, in situ hybridization of mRNA probes has provided evidence for a regional distribution of various combinations of these gene products.

In particular, the habenulo-interpeduncular system shows a high degree of expression of several of these genes. The medial habenular nucleus (MHB) gives rise to a large axonal projection (partly cholinergic) through the fasciculus retroflexus (FR) to the interpeduncular nucleus (IPN; for review, see Morley, 1986). Five genes $\left(\alpha_{3}, \alpha_{4}, \beta_{2}, \beta_{3}, \beta_{4}\right)$ are expressed in the MHB, and a different combination of five genes $\left(\alpha_{2}, \alpha_{3}, \alpha_{4}, \alpha_{3}, \beta_{2}\right)$ is found in the IPN. These areas also exhibit high-affinity binding for ${ }^{3} \mathrm{H}$-ACh and ${ }^{3} \mathrm{H}$-nicotine; they react with monoclonal antibodies directed against nAChRs, such as mAb-270 (Swanson et al., 1987) or mAb 35.76 (Deutch et al., 1987); they are regions where local glucose utilization increases in response to peripheral nicotine administration (London et al., 1988); and physiological responses to nicotine have been observed in both the MHB and the IPN (Brown et al., 1983, 1984; McCormick and Prince, 1987a). Finally, both pre- and postsynaptic nAChRs coexist in the IPN (Brown et al., 1984; Clarke et al., 1986). Habenular deafferentation experiments have further demonstrated (Clarke et al., 1986) that at least part of the presynaptic $n A C h R s$ in the IPN are located on MHB axon afferents. The MHB-IPN system thus appears to be an interesting model to study the functional diversity of nAChRs in the CNS.

We recently characterized a novel type of $\mathrm{nAChR}$ on the soma of MHB neurons using a preparation of acutely isolated neurons and patch-clamp techniques (Mulle and Changeux, 1990). We here describe the functional and pharmacological properties of nAChRs located in the IPN either at the postsynaptic level, that is, on the soma of acutely isolated neurons, or at the presynaptic level, that is, on axon terminals of afferent fibers to the IPN.

\section{Materials and Methods}

Characterization of $n A C h R s$ on IPN isolated neurons

Isolation of neurons. The procedure was derived from the method of Kay and Wong (1986) and from the method described in a previous 


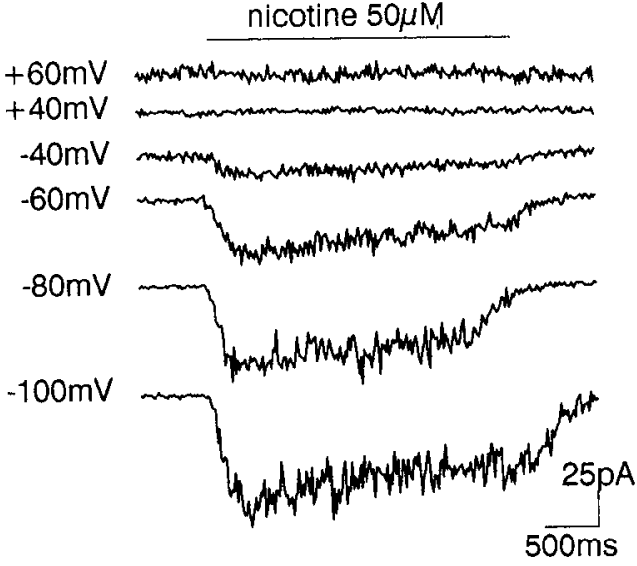

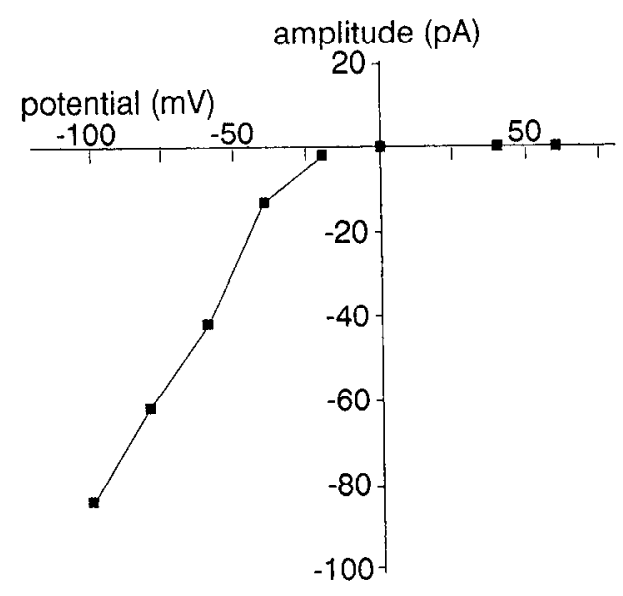

Figure 1. Whole-cell recordings (left) from a neuron freshly dissociated from the IPN. The current activated by nicotine was recorded at various holding potentials. The corresponding $I / V$ curve given on the right shows the intense inward rectification of the current at positive potentials. study (Mulle and Changeux, 1990). The brains from 15-20-d-old Sprague-Dawley rats were rapidly removed and placed in cold $\left(\approx 5^{\circ} \mathrm{C}\right)$ PIPES saline (in mM: $120 \mathrm{NaCl}, 5 \mathrm{KCl}, 5 \mathrm{MgCl}_{2}, 25$ D-glucose, 20 PIPES$\mathrm{NaOH} ; \mathrm{pH} 7$, equilibrated with $100 \% \mathrm{O}_{2}$ ). The IPN was dissected with a punch under a binocular microscope from a transverse slice that was cut manually (see Fig. 7), with little possibility of contamination by other surrounding brain regions. The tissue was incubated in $10 \mathrm{ml}$ PIPES saline containing $50 \mathrm{U}$ papain, $1 \mathrm{mg} / \mathrm{ml}$ bovine serum albumin, and $1 \mathrm{mg} / \mathrm{ml} \mathrm{L}$-cystein. It was stirred gently under pure $\mathrm{O}_{2}$ atmosphere at $35^{\circ} \mathrm{C}$ for $40 \mathrm{~min}$. The pieces of tissue were then rinsed several times in fresh PIPES saline. Cells were then triturated, centrifugated $5 \mathrm{~min}$ at $700 \mathrm{rpm}$, and then plated onto glass coverslips that had been coated previously with $5 \mu \mathrm{g} / \mathrm{ml}$ poly-L-ornithine in Dulbecco's modified Eagle's medium containing $25 \mathrm{~mm}$ HEPES and supplemented with Ultroser $\mathbf{G}$ (2\%) (IBF, France). The cells were allowed to settle on the coverslips in an incubator at $37^{\circ} \mathrm{C}$ for at least $1 \mathrm{hr}$ and were used on the same day.

This protocol was an improvement on the previously used technique (Mulle and Changeux, 1990) in several respects. In the incubator, cells tended to lose their neuritic processes, thus leading to isolated soma that were most suitable for whole-cell recordings and pharmacological experiments. Furthermore, the cells were significantly more solid, and stable recordings could be obtained for tens of minutes.

Electrophysiology on isolated neurons. Experiments were performed at room temperature. The cells were continuously superfused in a solution containing (in $\mathrm{mM}$ ) $150 \mathrm{NaCl}, 5 \mathrm{KCl}, 1 \mathrm{CaCl}_{2}, 1 \mathrm{MgCl}_{2}, 10$ HEPES-NaOH, and 10 D-glucose (pH 7.2). This solution and all drugs, unless otherwise stated, were applied by means of a multiple array of tubes that was moved laterally.

Macroscopic currents were recorded using the whole-cell variation of the patch-clamp technique. The solution in the patch pipette, unless otherwise stated, contained (in $\mathrm{mm}$ ) $140 \mathrm{CsCl}, 4 \mathrm{NaCl}_{2}, 2 \mathrm{MgCl}_{2}, 0.5$ $\mathrm{CaCl}_{2}, 5$ EGTA, and 10 HEPES. The solution was adjusted to $\mathrm{pH} 7.2$ with $\mathrm{CsOH}$. Single-channel activity was recorded in the outside-out mode. Under these experimental conditions, no single-channel activity was detected in the absence of cholinergic agonists. The currents were monitored with an Axopatch 1C (Axon Instruments, Inc., Burlingame, $\mathrm{CA}$ ), filtered at $2 \mathrm{kHz}$, stored on a Racal (Southampton, UK) FM analog tape recorder, fed into an IBM AT computer with an acquisition rate of $100 \mu \mathrm{sec} /$ point, and further analyzed with the program pCLAMP by Axon Instruments (Burlingame, CA; version 5.5). Single-channel amplitude was measured on all-point amplitude histograms (e.g., Fig. 2). Single-channel conductance was measured in patches where sufficient single-channel activity was recorded at at least four different potentials between -40 and $-100 \mathrm{mV}$. All values are given as mean \pm SD.

\section{Preparation of slices containing the $F R$ and the IPN and field potential recordings}

Adult male Sprague-Dawley rats were decapitated under ether anesthesia, and the brains were rapidly removed. Two parasagital sections were made $1 \mathrm{~mm}$ apart from the midline, and the side tissues were removed. The tissue block was laid on a side, and a first cut was made manually $1-1.5 \mathrm{~mm}$ rostral and parallel to a virtual line joining the
MHB to the IPN. The following cuts were made with a McIllwain tissue choppcr $(500-\mu \mathrm{m}$-thick slices). $\Lambda$ single slice per animal could be obtained that included both FRs entering bilaterally the rostral part of the IPN (see Fig. 7).

The slice was incubated in artificial cerebrospinal fluid for $1 \mathrm{hr}$ and then placed in a recording chamber perfused with a medium containing (in mM) $124 \mathrm{NaCl}, 3.5 \mathrm{KCl}, 1.3 \mathrm{MgSO}_{4}, 2.5 \mathrm{CaCl}_{2}, 26 \mathrm{NaHCO}_{3}, 1.25$ $\mathrm{NaH}_{2} \mathrm{PO}_{4}$, and 10 glucose and gassed with $95 \% \mathrm{O}_{2}, 5 \% \mathrm{CO}_{2}$ at $36.5^{\circ} \mathrm{C}$. The flow rate was $2 \mathrm{ml} / \mathrm{min}$, and a new perfusion solution reached the chamber within 1.5-2 min. A bipolar tungsten stimulation electrode was placed at the entry point of one of the MHB-IPN tracts into the IPN. A recording glass microelectrode filled with $3 \mathrm{M} \mathrm{NaCl}, 5-20 \mathrm{M} \Omega$, was placed in the rostral IPN subnucleus (nomenclature of Hamill and I enn, 1984). A single shock stimulation of one FR produced an extracellular field potential consisting mainly of a large negative wave (downward deflection as compared to basclinc), the amplitude of which was considered for field potential measurements. A conventional high-inputresistance amplifier was used for voltage recordings. The data were analyzed using a digital oscilloscope.

\section{Compounds}

$\mathrm{CsOH}$ was from Aldrich. Dihydro- $\beta$-erythroidine (DHBE) was donated by Merck, Sharp, and Dohme. Neuronal bungarotoxin (NBT) was from Biotoxins. All other compounds were from Sigma.

\section{Results}

\section{nAChRs on isolated IPN neuronal soma}

\section{Characteristics of macroscopic nicotinic currents}

Neurons in the IPN were most often round to slightly elongated, with a diameter of 10-15 $\mu \mathrm{m}$. In whole-cell recordings, neurons were identified by the presence of a large (several hundreds of pA) $\mathrm{Na}^{+}$current in response to a depolarizing pulse, which inactivated in a few msec. $\mathrm{K}^{+}$currents were almost completely abolished by the presence of $\mathrm{Cs}^{+}$in the patch pipette medium.

Nicotine $(50 \mu \mathrm{M})$ was generally used as an agonist, in preference to $\mathrm{ACh}$, to avoid activation of muscarinic receptors. Approximately 50\% of the neurons tested responded to $\mathrm{ACh}$ or nicotine application. In over 200 neurons, $\mathrm{ACh}$ and/or nicotine evoked, without any delay ( $\leq 100 \mathrm{msec}$ after onset of perfusion), an inward current accompanied by an increase in noise (Fig. 1). The mean amplitude of the response was $76 \pm 40 \mathrm{pA}$ (range, $10-480 \mathrm{pA} ; n=153$ cells) for $50 \mu \mathrm{M}$ nicotine at a holding potential of $-80 \mathrm{mV}$.

The inward current activated by nicotine decreased with depolarization (Fig. 1) and reached 0 value between -20 and -10 $\mathrm{mV}$ (apparent reversal potential). The current rectified strongly, and no outward current was observed at positive values of the 


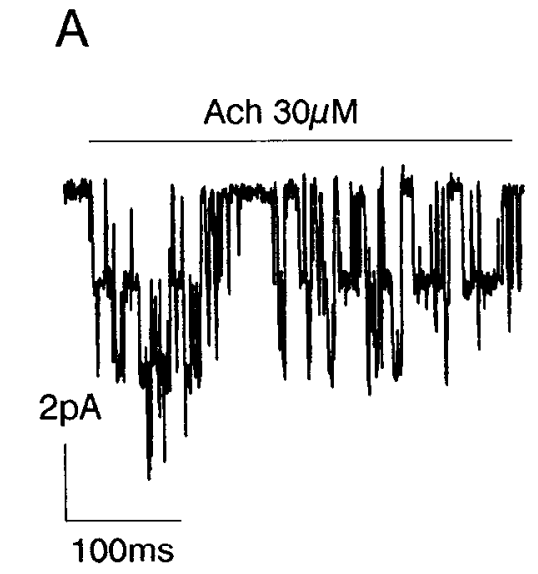

number of points

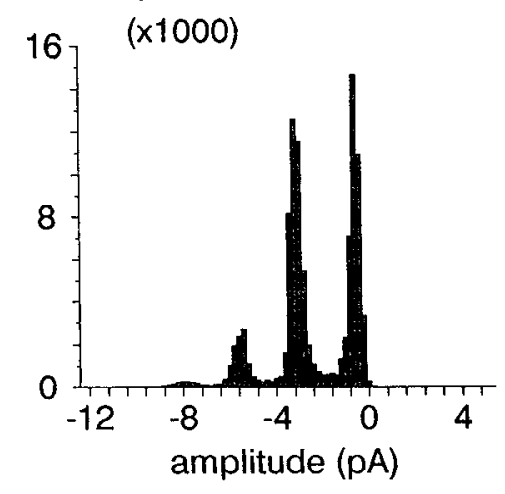

B

Figure 2. Single-channel currents evoked by $\mathrm{ACh}$ and nicotine recorded in outside-out patches from two different cells. $A$, Addition of ACh results in the simultaneous opening of several channels. All channels display the same unitary current, as demonstrated on the right in the corresponding all-points amplitude histogram. Membrane potential was held at $-80 \mathrm{mV}$. $B$, In another cell, nicotine-activated channels were recorded (left) at various holding potentials in the presence of $50 \mu \mathrm{M}$ nicotine. On the right is given the corresponding current-voltage relationship. Linear regression between -40 and $-100 \mathrm{mV}$ gives an elementary conductance of $35 \mathrm{pS}$ and an apparent reversal potential of $-20 \mathrm{mV}$.

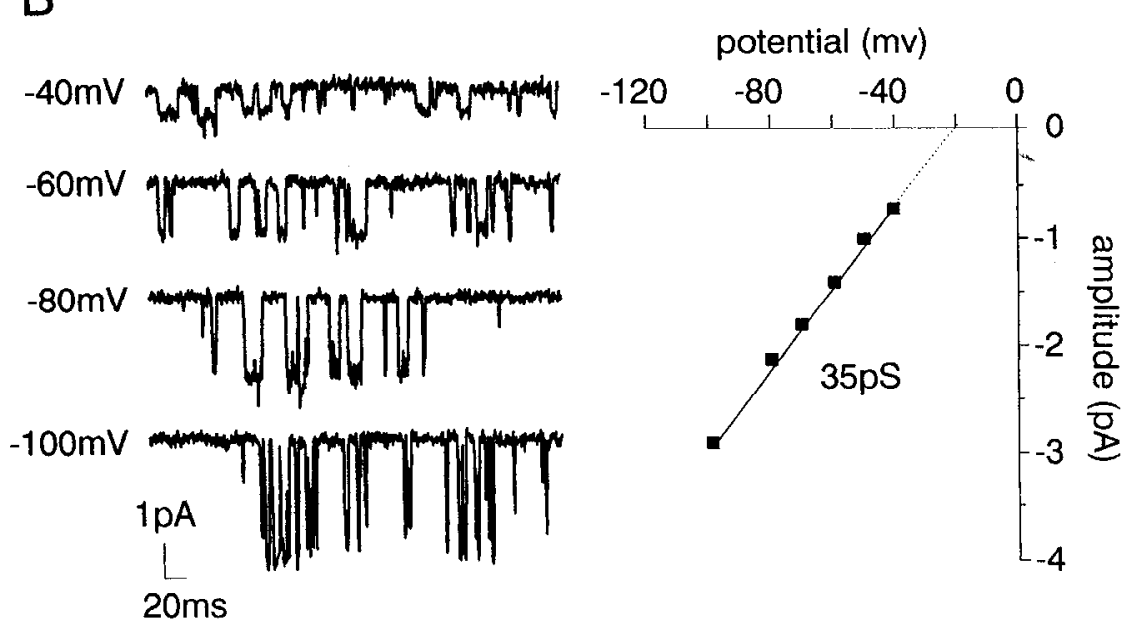

holding potential, at least up to $+60 \mathrm{mV}$. The value of the apparent reversal potential was compatible either with a nonselective cationic current or with an anionic $\left(\mathrm{Cl}^{-}\right)$current. Substitution of $\mathrm{Cl}^{-}$in the patch pipette with gluconate or glutamate did not affect the apparent reversal potential. These results suggest that the inward current activated by $\mathrm{ACh}$ and nicotine is relatively nonselective for cations.

\section{Single-channel recordings}

Outside-out recordings were made from membrane patches obtained from the soma of neurons that displayed a typical inward current in response to the application of nicotine or ACh. At potentials below $-60 \mathrm{mV}$, these patches were totally inactive in the absence of the agonist. Some patches did not display any single-channel activity even in the presence of the agonist. This was probably due to the low density of nAChRs on some IPN neurons. However, generally, single-channel currents were activated upon perfusion with ACh or nicotine, without any delay, under minimal conditions of intracellular medium composition (no ATP or GTP). The activity of nicotinic channels disappeared within 2 or $3 \mathrm{~min}$, independent of the nature and concentration of agonist and of the duration of application of the agonist. This rundown phenomenon could not be reversed by addition of ATP $(2 \mathrm{mM})$ or leupeptin $(100 \mu \mathrm{M})$ in the pipette solution.

In almost all recordings, only a single class of current ampli- tude was detected, as illustrated in Figure $2 A$, where several channels were simultaneously active. The apparent reversal potential was $-16 \pm 6 \mathrm{mV}(n=33)$. Nicotinic channel activity was not observed at positive potentials. This could be due to the low probability of opening of the channel, as proposed for rat superior cervical ganglion nAChRs by Mathie et al. (1990). Most values of single-channel conductance fell within the range of $30-42 \mathrm{pS}$. The mean value for single-channel conductance was $34.9 \pm 4.2 \mathrm{pS}(n=33)$ when nicotine was used as the agonist and $34.0 \pm 3.0 \mathrm{pS}(n=7)$ with ACh.

\section{Pharmacological properties}

In whole-cell recordings, inward currents were also activated by cytisine and dimethylphenylpiperazinium (DMPP; Fig. 3), which act as agonists on ganglionic nAChRs, but not by muscarine $(10 \mu \mathrm{M})$. We estimated the relative efficacy of nicotinic agonists by comparing the amplitude of the current evoked by various concentrations of these agonists (up to $1 \mathrm{~mm}$ ) to the amplitude of the current evoked by a test application of $50 \mu \mathrm{m}$ nicotine (Figs. 3, 4). The fit of the dose-response curves gave estimated Hill coefficients ranging between 1.3 and 1.7 (Fig. 4), suggesting the presence of at least two binding sites for the agonist. The estimated values of the apparent $K_{d} \mathrm{~s}$ were all in the same range $(28-43 \mu \mathrm{M})$, but there were marked differences in the maximal amplitudes of the current evoked by these agonists (Fig. 4): the 

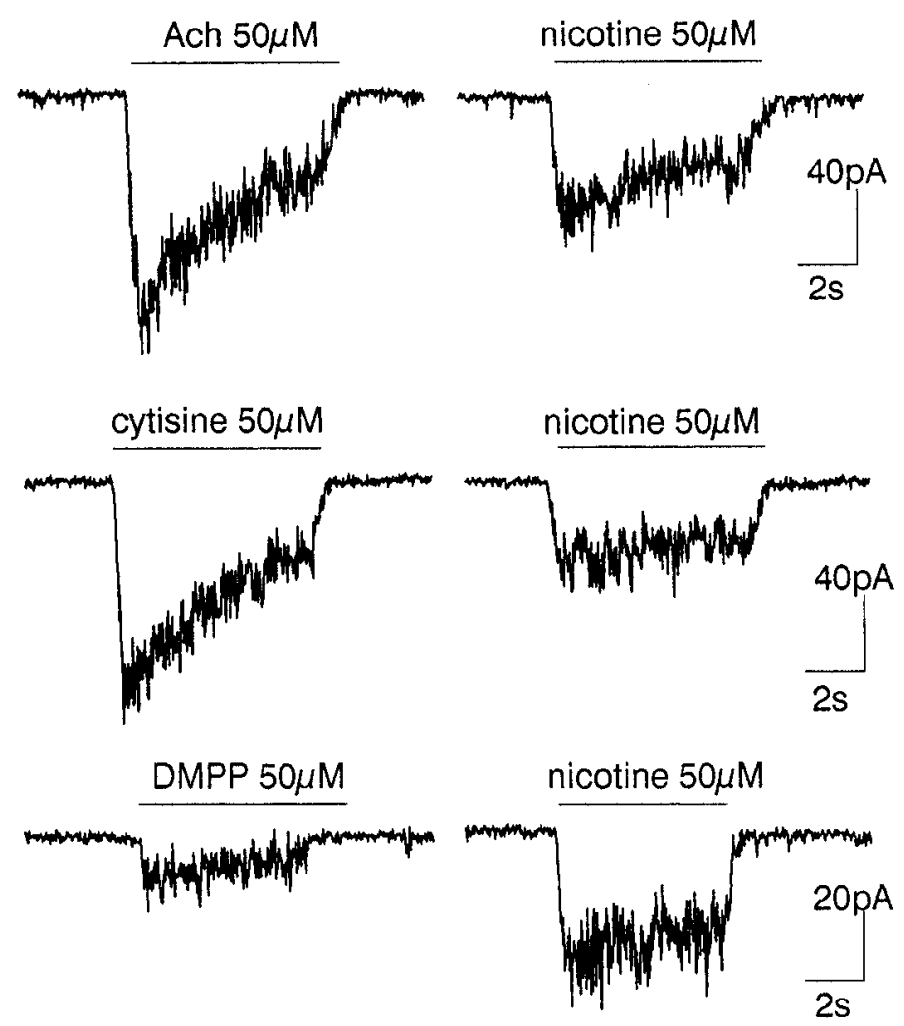

Figure 3. Response of IPN neurons to various nicotinic agonists compared to the response to $50 \mu \mathrm{M}$ nicotine. Each pair of recordings is from different cells. The membrane potential was held at $-80 \mathrm{mV}$.

rank order of agonist efficacy was cytisine $>\mathrm{ACh}>$ nicotine $>$ DMPP. The current evoked by ACh was unchanged in the presence of eserine $(10 \mu \mathrm{M})$, an $\mathrm{AChE}$ inhibitor. Figure 3 also shows that the response to ACh progressively desensitizes during prolonged application of the agonist, an effect that was rapidly reversible. The rate of desensitization increased with increasing concentration of agonist: the half decay times were $\geq 10 \mathrm{sec}$ at $3 \times 10^{-5} \mathrm{M} \mathrm{ACh}(n=6), 4.3 \pm 0.5 \mathrm{sec}$ at $10^{-4} \mathrm{M} \mathrm{ACh}(n=6)$, $2.3 \pm 0.7 \mathrm{sec}$ at $3 \times 10^{-4} \mathrm{M}(n=5)$, and $1.7 \pm 0.5 \mathrm{sec}$ at $10^{-3}$ M $(n=4)$.

We occasionally recorded nicotinic responses of low amplitude $(<20 \mathrm{pA})$ that were more sensitive to DMPP and ACh than to nicotine and cytisine. Because of their low amplitude, these responses were not further analyzed, but this observation raises the possibility that additional types of $n A C h R s$ exist in the IPN.

The nicotinic response was blocked by various classical ganglionic antagonists (mecamylamine, curare, hexamethonium, DHBE; Fig. 5). The effects of all the antagonists tested were rapidly reversible (in less than $30 \mathrm{sec}$ ) when the agonist was removed from the bath before subsequent test application. Doseresponse curves were obtained, with a test application of $50 \mu \mathbf{M}$ nicotine and at a holding potential of $-80 \mathrm{mV}$, after correction for the slow desensitization of the response to nicotine. The values of the $\mathrm{IC}_{50}$ mcasurcd under these conditions are given in Table 1. No attempt was made to study the mode of action of these antagonists.

$\alpha$-Bungarotoxin ( $\alpha \mathrm{BGT})$, a potent nicotinic blocker at the neuromuscular junction, applied at a concentration of $500 \mathrm{~nm}$ either for more than $5 \mathrm{~min}$ in the bath during recording $(n=4)$ or for $30 \mathrm{~min}$ before recording, did not affect the response to nicotine.
Table 1. $\mathrm{IC}_{50}$ values of various antagonists for $\mathrm{nAChRs}$ located on the soma of IPN or MHB neurons and on presynaptic axon afferents to the IPN

\begin{tabular}{llll} 
& \multicolumn{2}{l}{ IPN $(\mu \mathrm{M})$} & \\
\cline { 2 - 3 } Antagonists & nAChRs & $\begin{array}{l}\text { Presynaptic } \\
\text { afferents }\end{array}$ & MHB nAChRs $(\mu \mathrm{M})$ \\
\hline Mecamylamine & 0.1 & 2 & 0.01 \\
Hexamethonium & 1 & 4 & 0.5 \\
DHRE & 2 & 250 & 30 \\
Curare & 2 & 200 & 0.2 \\
NBT & - & - & -
\end{tabular}

The effects of the antagonists were tested on the response to $50 \mu \mathrm{M}$ nicotine, as indicated in Figures 4 and 9 captions.

NBT was tested after preincubation of the cells with the toxin for more than $30 \mathrm{~min}$. The amplitude of the response to $50 \mu \mathrm{M}$ nicotine, measured in three different dishes with NBT (500 nM), was $60 \pm 30 \mathrm{pS}(n=7)$, a value not significantly different from control. Atropine, at a concentration $(1 \mu \mathrm{M})$ that totally blocks muscarinic responses in other systems, was without effect.

\section{Comparison between $n A C h R s$ from IPN and $M H B$ isolated neurons}

We recently characterized an $\mathrm{nAChR}$ on the soma of MHB neurons (Mulle and Changeux, 1990) that had been isolated according to a protocol different from the one used in the present study. In order to compare reliably the characteristics of $\mathrm{nAChRs}$ in the IPN and in the MHB under equivalent experimental conditions, we tested the electrophysiological and pharmacological characteristics of $\mathrm{nAChRs}$ on $\mathrm{MHB}$ neurons isolated according to this new protocol. Experiments were performed on 10-15-d-old animals. ACh and/or nicotine activated an inward current relatively nonselective for cations that rectified strongly at positive holding potentials. Outside-out recordings revealed a single class of nicotine-activated single channels. The singlechannel conductance given as the slope of the $I / V$ curve between -40 and $-80 \mathrm{mV}$ was $41.3 \pm 3.8 \mathrm{pS}(n=13)$. This value is significantly different from that found for IPN nAChRs. This value also differs from the one we had reported in our previous study for MHB neurons. The reason for this discrepancy is unclear. The possibility that a different type of $\mathrm{nAChR}$ was activated seems unlikely because, under equivalent test conditions (holding potential of $-60 \mathrm{mV}$, test application of $10 \mu \mathrm{M}$ nicotine), we found no difference in the sensitivity to several nicolinic agonists and antagonists with the data reported in our previous work. Another possible explanation for the noted difference in single-channel conductance is that the former isolation protocol favors a subconductance state of the $\mathrm{nAChR}$, as observed with other preparations (see, e.g., Papke et al., 1989a).

The pharmacological properties of nicotinic responses in MHB and IPN isolated neurons were compared under identical experimental conditions. The amplitude of the macroscopic currents evoked by various concentrations of several nicotinic agonists relative to the amplitude of currents activated by a test application of $50 \mu \mathrm{M}$ nicotine gave dose-response curves with $K_{d}$ values ranging between 32 and $60 \mu \mathrm{M}$ and Hill coefficients ranging between 1.3 and 1.8 . The rank order of potency of these agonists (nicotine $>$ cytisine $>$ ACh $>$ DMPP) clearly differs from that found for IPN nAChRs (Table 2). The relative efficacy of several nicotinic antagonists on MHB and IPN nAChRs (test 

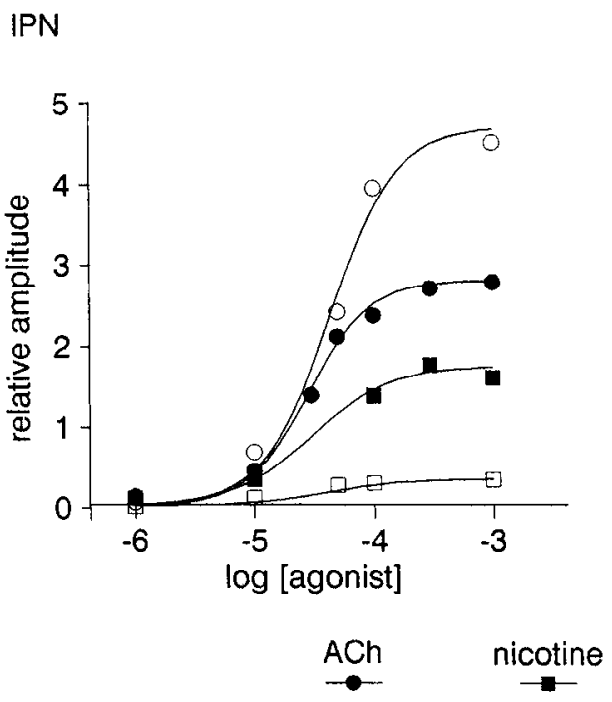

MHB

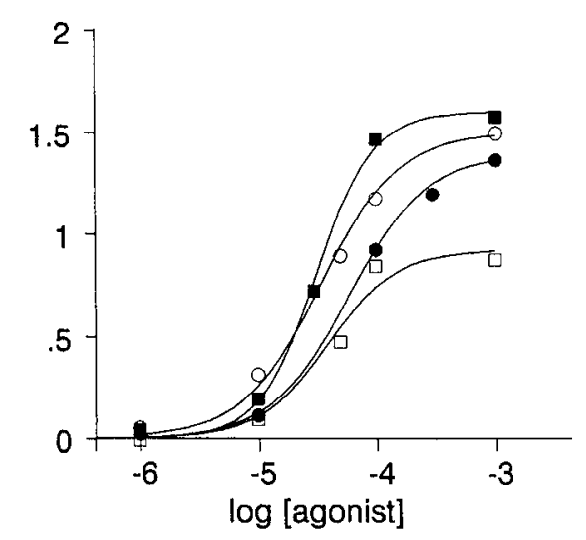

cytisine

Figure 4. Comparison of the sensitivity of several nicotinic agonists in the IPN and in the MHB. Dose-response curves were obtained by comparing the peak amplitude of the current evoked by various concentrations of agonist to that evoked by $50 \mu \mathrm{M}$ nicotine in the same cell. Each point represents the mean of at least three different measurements in three different cells. Dose-response curves were fit with the function $A_{\max } /\left(1+\left(K_{d} /\right.\right.$ [agonist] $)^{n}$ ), where $A_{\max }$ is relative amplitude measured at a saturating concentration of agonist. In a few cases, saturation of response was not completely attained; thus, the $A_{\max }$ used for fitting dose-response curves was slightly underestimated. The estimate values of the different parameters for IPN nAChRs were $A_{\max }=2.7, K_{d}=28 \mu \mathrm{M}$, and $n=1.7$ for $\mathrm{ACh} ; A_{\max }=1.7, K_{d}=30 \mu \mathrm{M}$, and $n-1.3$ for nicotine; $A_{\max }-4.6, K_{d}-43 \mu \mathrm{M}$, and $n=1.5$ for cytisine; and $A_{\max }=0.3, K_{d}=40 \mu \mathrm{M}$, and $n=1.3$ for DMPP. The estimate values of the different parameters for MHB nAChRs were $A_{\max }=1.4, K_{d}=60 \mu \mathrm{M}$, and $n=1.3$ for $\mathrm{ACh} ; A_{\max }=1.6, K_{d}=32 \mu \mathrm{M}$, and $n=1.8$ for nicotine; $A_{\max }=1.5, K_{d}=35 \mu \mathrm{M}$, and $n=1.3$ for cytisine; and $A_{\max }=0.9, K_{d}=48 \mu \mathrm{M}$, and $n=1.3$ for DMPP.

application of $50 \mu \mathrm{M}$ nicotine, holding potential of $-80 \mathrm{mV}$ ) were compared in Figure 6 and in Table 1. There are major differences in the sensitivities of MHB and IPN AChRs to DHBE ( $\times 15$-fold), mecamylamine $(\times 10$-fold $)$, and curare $(\times 10$-fold $)$. However, as for IPN nAChRs, incubation of MHB neurons for over 30 min with NBT did not significantly inhibit the response to nicotine (test application of $50 \mu \mathrm{M}$ nicotine, control: mean amplitude $=1070 \pm 880 \mathrm{pA}, n=11 ; \mathrm{NBT}, 500$ nM: mean amplitiude $=820 \pm 350 \mathrm{pA}, n=7)$.

\section{Pharmacological profile of IPN presynaptic nAChRs}

Wc also described the pharmacological profile of putative presynaptic nAChRs located on the axon terminals of the FR by recording the afferent volley evoked by the stimulation of the FR in a slice preparation containing the terminal portion of the FR and the IPN (Fig. 7), as described by Brown et al. (1984). In the present experiments, the recording electrode was positioned in the central part of the rostral subnucleus of the IPN. A brief stimulation $(0.2 \mathrm{msec})$ of one FR at the level of its entry point in the IPN produced an extracellular negative field potential, the amplitude of which increased linearly with stimulation intensity, while the latency to peak decreased. The field potential exhibited the characteristics of an afferent volley (Brown et al., 1984 ) in that (1) it was not depressed when synaptic transmission was blocked with a medium containing no $\mathrm{Ca}^{+}$and high $\mathrm{Mg}^{+}$, (2) it followed high-frequency stimulation rates, and (3) it was not affected by an iontophoretic application of glutamate known to depolarize IPN neurons. The negative field we recorded thus represented the sum of action potentials evoked in the bundles of axons traveling to the IPN.

In every slice studied $(n=41)$, the addition of nicotine to the perfusion medium reversibly decreased the amplitude and latency of the afferent volley (Fig. 8). This effect, which was also observed with a high $\mathrm{Mg}^{2+} / 0 \mathrm{Ca}^{2+}$ medium, can be interpreted as a depolarization of the FR axons due to the activation of presynaptic $\mathrm{nAChR}$ channels. The action of nicotine was dose dependent and was mimicked by several cholinergic agonists with the following order of potency: nicotine $\left(\mathrm{EC}_{50}, 10 \mu \mathrm{M}\right)>$ cytisine $\left(\mathrm{EC}_{50}, 50 \mu \mathrm{M}\right)>\mathrm{ACh}$ in the presence of eserine $(10 \mu \mathrm{M})$ $\left(\mathrm{EC}_{50}, 100 \mu \mathrm{M}\right)$ and carbachol $\left(\mathrm{EC}_{50}, 100 \mu \mathrm{M}\right)>\mathrm{DMPP}\left(\mathrm{EC}_{50}\right.$, $200 \mu \mathrm{M})$. The addition of atropine $(1-10 \mu \mathrm{M})$ did not affect the action of ACh.

The pharmacological action of various nicotinic antagonists was analyzed by comparing the effects of a 5 -min perfusion with $50 \mu \mathrm{M}$ nicotine to those of various concentrations of antagonists applied together with $50 \mu \mathrm{M}$ nicotine for $5 \mathrm{~min}$. Hexamethonium and mecamylamine blocked the effect of nicotine on the afferent volley with an $\mathrm{IC}_{50}$ of 4 and $3 \mu \mathrm{M}$, respectively (Figs. 8, 9). Curare and DHBE blocked nicotine action at higher concentrations, with $\mathrm{IC}_{50}$ values of 200 and $250 \mu \mathrm{M}$, respectively. In contrast, NBT did not affect the action of nicotine when applied at concentrations up to $1.4 \mu \mathrm{M}$ either with nicotine $(n=3)$ or after preincubation for over $15 \mathrm{~min}$ before the application of nicotine $(n=3$; Fig. 8). $\alpha$ BGT $(1-3 \mu \mathrm{M})$ did not block the effect of nicotine either. None of the antagonists tested had any effects by themselves on the amplitude of the afferent volley. Their action was rapidly reversible, except for mecamylamine, for which a recovery period of at least $1 \mathrm{hr}$ was necessary.

Table 2. Rank order of efficacy of agonists

\begin{tabular}{ll} 
Location & Rank order of efficacy \\
\hline IPN soma & cytisine $>$ ACh $>$ nicotine $>$ DMPP \\
IPN presynaptic afferents & nicotine $>$ cytisine $>$ ACh $>$ DMPP \\
MHB soma & nicotine $>$ cytisine $>$ ACh $>$ DMPP
\end{tabular}

This table shows the rank order of efficacy of various agonists on nAChRs located on the soma of IPN and MHB neurons (see Figs. 3,4) and on presynaptic axon afferents to the IPN (see Fig. 9). 
curare

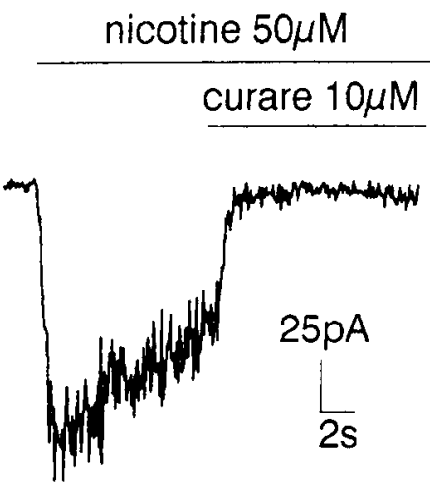

hexamethonium

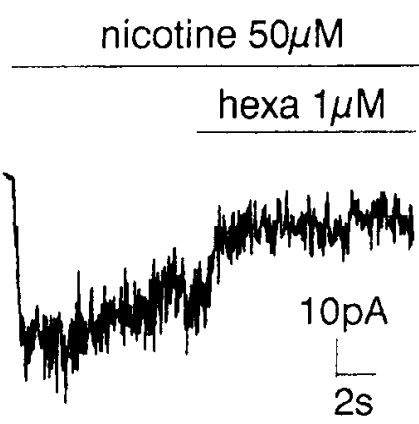

nicotine $50 \mu \mathrm{M}$

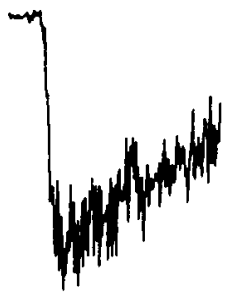

nicotine $50 \mu \mathrm{M}$

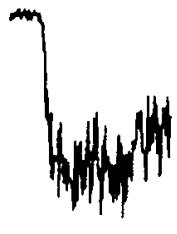

mecamylamine

nicotine $50 \mu \mathrm{M}$

nicotine $50 \mu \mathrm{M}$

meca $1 \mu \mathrm{M}$
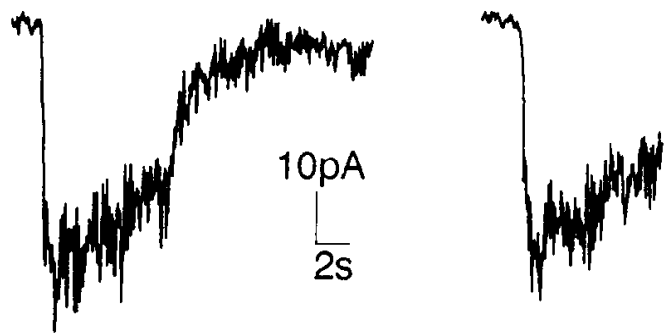

\section{dihydro-ß-erythroidine}

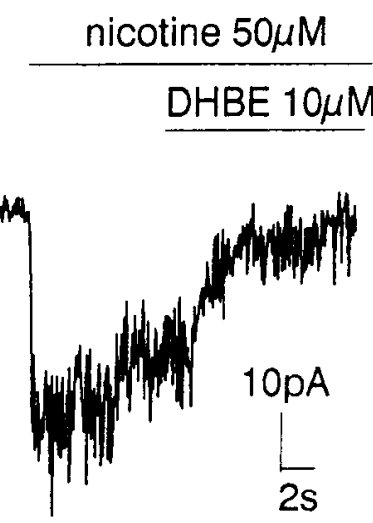

nicotine $50 \mu \mathrm{M}$

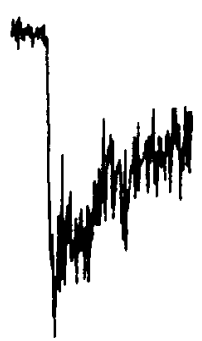

Figure 5. Effects of various nicotinic antagonists on the response to $50 \mu \mathrm{M}$ nicotine. The membrane potential was held at $-80 \mathrm{mV}$. Antagonists were applied together with nicotine by means of an array of microcapillary tubes that was moved laterally. hexa, hexamethonium; meca, mecamylamine.

mecamylamine

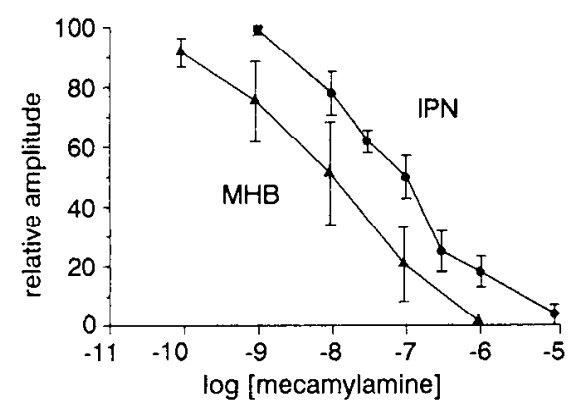

hexamethonium

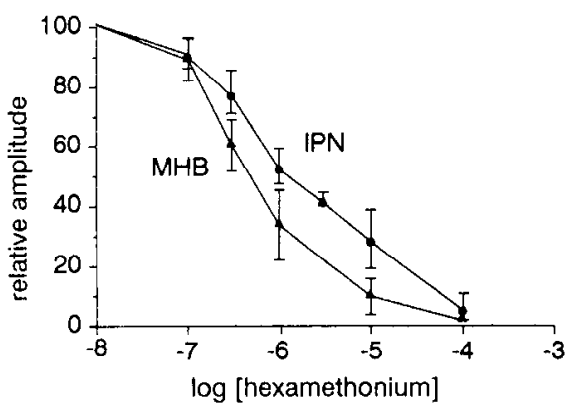

dihydro-ß-erythroidine

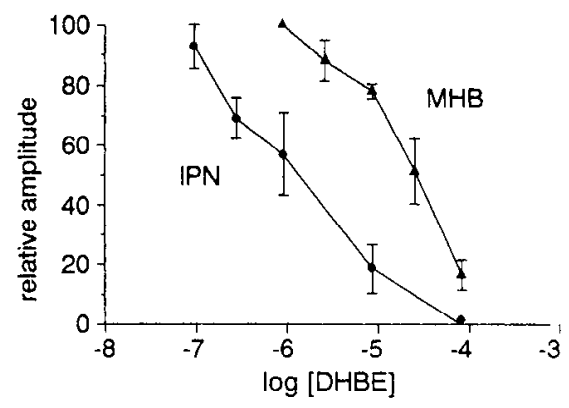

curare

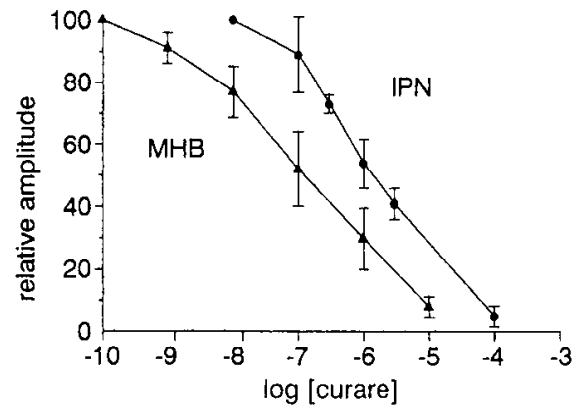

Figure 6. Comparison of the effects of various antagonists on $\mathrm{nAChRs}$ recorded on isolated IPN and MHB neurons. Dose-response curves were obtained under equivalent experimental conditions (test application of $50 \mu \mathrm{M}$ nicotine, holding potential of $-80 \mathrm{mV}$ ), by comparing the amplitude of the current just before the application of the antagonist to $5 \mathrm{sec}$ after its onset. Each point represents the mean $( \pm S D)$ of at least three different measurements. 


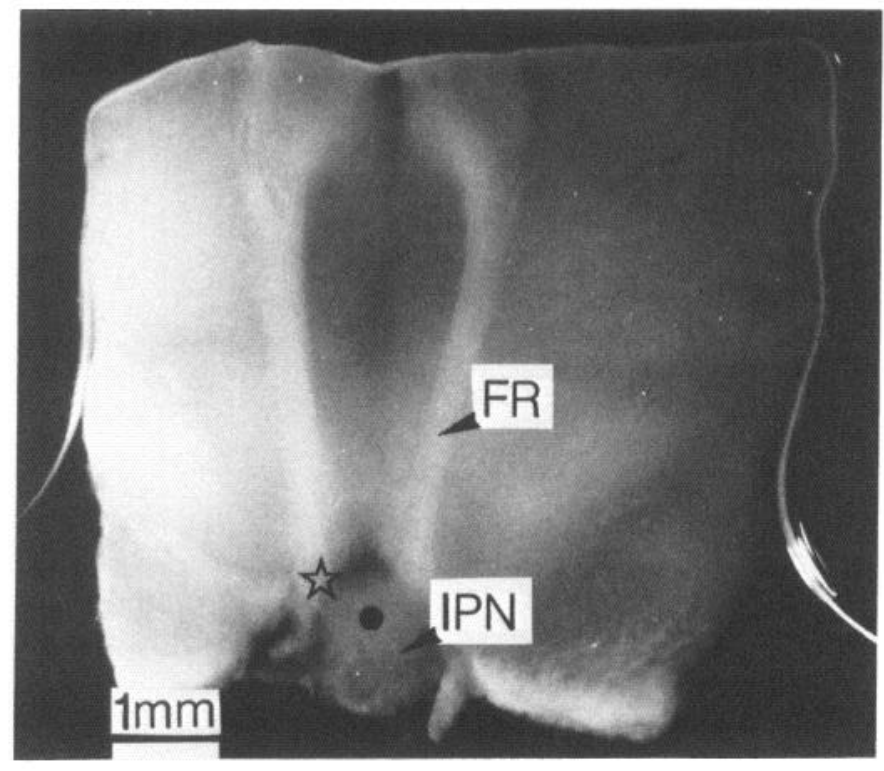

Figure 7. Transverse slice including both FR and the rostral part of the IPN. The circle and the star indicate, respectively, the approximate location of the recording and the stimulating electrodes.

\section{Discussion}

In the present article, we provide electrophysiological and pharmacological evidence for the existence of several distinct subtypes of nAChRs in the rat CNS. The MHB-IPN system, a chain of cholinoceptive neurons, was used to compare tentatively nAChRs located (1) in different brain regions, (2) at preand postsynaptic sites in a given synapse, and (3) on the soma and on axon terminals in a given neuron.

In situ hybridization experiments have revealed the discrete and differential expression of several genes encoding neuronal nAChR subunits in the CNS. On the other hand, electrophysiological studies, using mainly extracellular recordings, have demonstrated the existence of functional $\mathrm{nAChRs}$ in various regions of the vertebrate CNS (Brown et al., 1984; Clarke et al., 1985; Egan and North, 1986; De la Garza et al., 1987; McCor-

\section{A agonists}

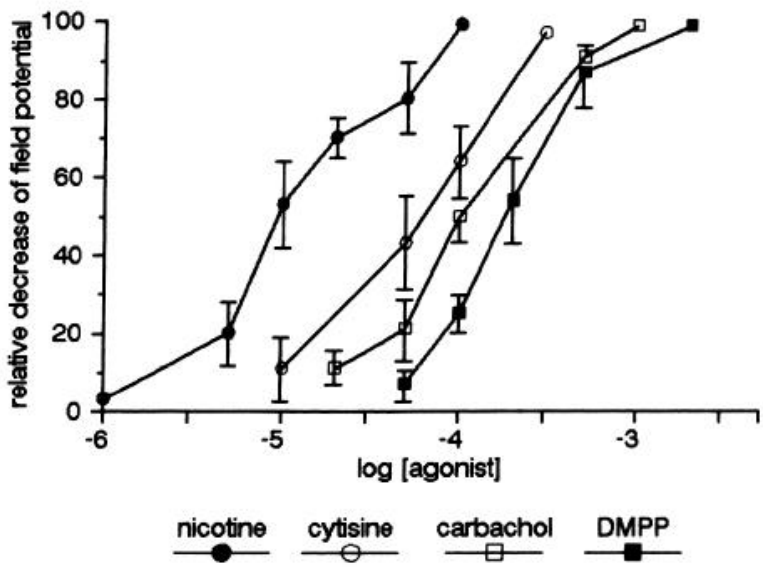

$B$ antagonists

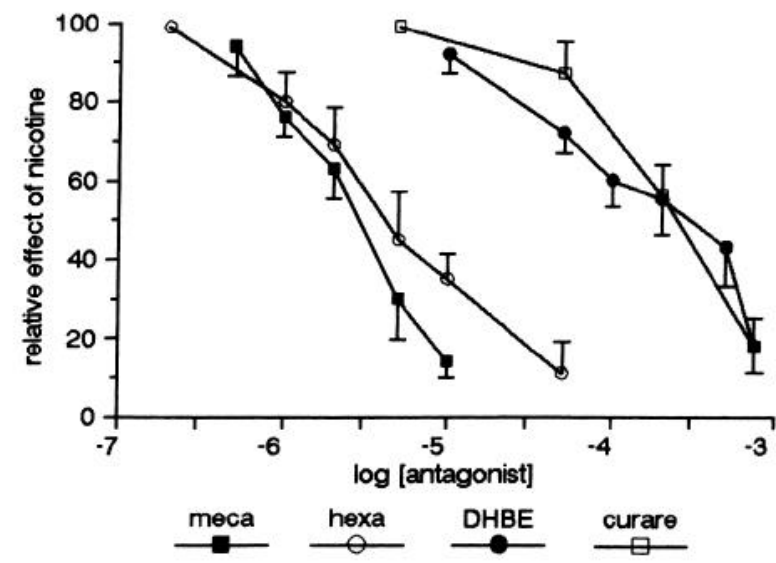

Figure 9. A, Dose-response curves for the relative decrease of the amplitude of the evoked field potential by various agonists. $B$, Doseresponse curves for the relative effects of $50 \mu \mathrm{M}$ nicotine on the amplitude of the evoked field potential, in the presence of various concentrations of nicotinic antagonists. Each point represents the mean $( \pm \mathrm{SD})$ of at least three different measurements made in three different slices. meca, mecamylamine; hexa, hexamethonium.
Figure 8. Effects of nicotine on the afferent volley recorded in the IPN and blockade of the effect of hexamethonium but not by NBT. Perfusion with 10 $\mu \mathrm{M}$ nicotine $(N)$ decreased the afferent volley potential $(a, b)$. Addition of hexamethonium ( $\mathrm{Hex} ; 5 \mu \mathrm{M})$ to nicotine $(10 \mu \mathrm{M})$ reversibly abolished the effect of nicotine $(c, d)$. Perfusion with NBT $(1.4 \mu \mathrm{M})$ for $10 \mathrm{~min}$ did not block the action of nicotine $(e-g)$.
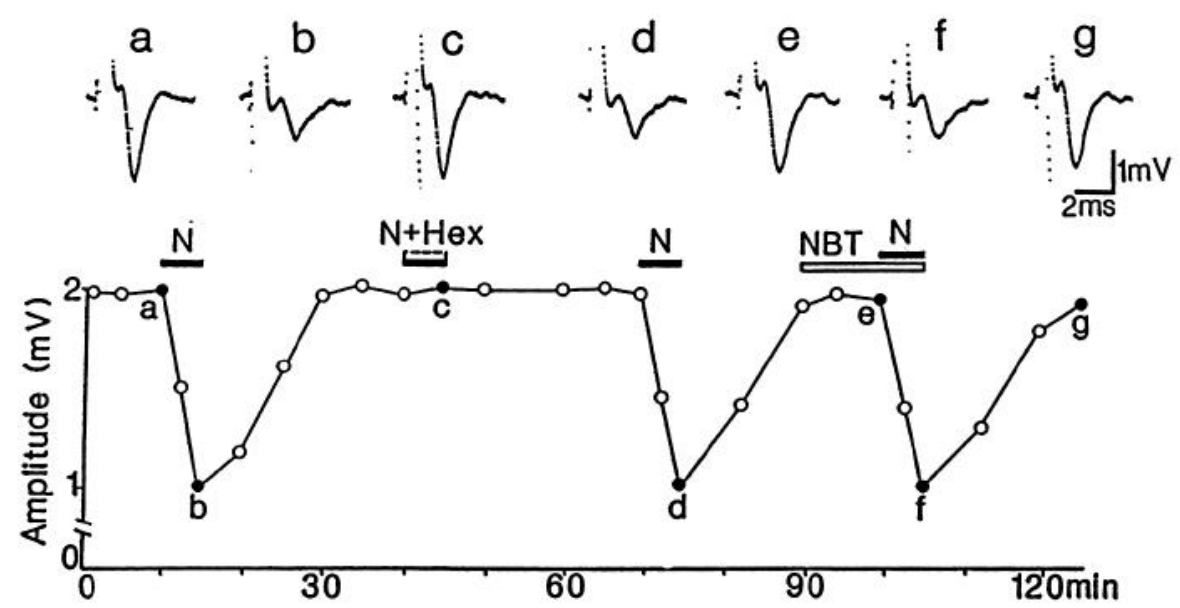
mick and Prince, 1987a,b; Vidal and Changeux, 1989; Sorenson and Chiappinelli, 1990). However, no systematic comparison of the pharmacological and physiological properties of the receptors present in these different areas had yet been performed. Direct characterization of nAChRs in the CNS by patch-clamp techniques has only been obtained in primary cultures of retinal ganglion cells (Lipton et al.,1987) and hippocampal neurons (Aracava et al., 1987), and in acutely isolated MHB neurons (Mulle and Changeux, 1990). In the present article, we have described the functional and pharmacological characteristics of nAChRs located at pre- and postsynaptic sites in the IPN and have compared the properties of these receptors to those already described in the MHB.

We first compared the properties of $n A C h R s$ found on the soma of IPN and MHB neurons. The IPN and the MHB cxpress different combinations of neuronal nAChR genes, that is, hybridization with $\alpha_{2}, \alpha_{3}, \alpha_{4}, \alpha_{5}$, and $\beta_{2}$ RNA probes in the IPN and hybridization with $\alpha_{3}, \alpha_{4}, \beta_{2}, \beta_{3}$, and $\beta_{4}$ RNA probes in the MHB. We have used identical experimental conditions for the characterization of IPN and MHB nAChRs. In both these nuclei, $\mathrm{ACh}$ and classical nicotinic agonists activate channels that appear to be nonselective for cations as well as for muscle and ganglionic nAChRs (Adams, 1980; Fenwick et al., 1982). They both show intense inward rectification, and no outward current can be observed in response to cholinergic agonists at positive holding potentials up to $+50 \mathrm{mV}$. Inward rectification seems to be a common property for $\mathrm{nAChRs}$ in ganglia (Hirano et al., 1987; Ifune and Steinbach, 1990; Mathie et al., 1990) and has also been shown to occur with oocyte-expressed nAChRs (Bertrand et al., 1990; Couturier et al., 1990a,b), but this property is not shared with muscle nAChRs. In both nuclei, single-channel measurements revealed the presence of a single class of elementary nicotinic currents on patches taken from the soma. This finding contrasts with the diversity of genes expressed in both these nuclei, as indicated by in situ hybridization studies. Because we have only characterized $\mathrm{nAChRs}$ located on cell bodies, a possible explanation is that several subtypes of $n A C h R s$ can coexist in a single neuron, but are located at distinct cellular levels. The single-channel conductances in the MHB (41.3 pS) and in the IPN (34.9 pS) were significantly different. The nAChRs also differed in their sensitivity to nicotinic agonists and antagonists. However, in both regions, $\mathrm{nAChRs}$ were not only insensitive to $\alpha \mathrm{BGT}$, but also to NBT, a toxin that completely blocks $\mathrm{nAChRs}$ in other regions of the CNS, such as retinal ganglion cells (Lipton et al., 1987), prefrontal cortex (Vidal and Changeux, 1989), and striatum (Schulz et al., 1989).

We have also compared pre- and postsynaptic $\mathrm{AChR}$ within the IPN. Because of the impossibility of recording from nerve terminals, the pharmacology of presynaptic nAChRs has been assessed by measuring the effects of nicotinic agonists on the afferent volley produced by stimulation of the FR. The present results confirm and extend the study of Brown et al. (1984). The pharmacological characterization of pre- and postsynaptic nAChRs were performed under experimental conditions that were obviously different, so these results must be examined with caution. The relative potency of several nicotinic agonists was different for pre- and postsynaptic nAChRs (Table 2). Both preand postsynaptic receptors were insensitive to $\alpha \mathrm{BGT}$ and to NBT. However, we observed a marked difference in the potency of DHBE and postsynaptic nAChRs in inhibiting the response to nicotine. The main impairment in indirectly recording from presynaptic fibers is that we do not control the membrane po- tential, so that comparison will only be valuable for antagonists whose effects are not dependent on voltage. Preliminary indications show that the effect of curare increases with voltage, but the effect of DHBE is voltage independent. Thus, our results strongly support the conclusion that pre- and postsynaptic nAChRs within the IPN are pharmacologically different.

The exact subunit composition of the different nAChRs in the CNS is not established. Comparison of our data with data from oocyte expression experiments can give some clues to this issue. Neuronal nAChRs from rat and chicken expressed in oocytes have been recently tested for their sensitivity to various toxins (Ballivet et al., 1988; Wada et al., 1988; Duvoisin et al., 1989; Couturier et al., 1990a; Luetje et al., 1990) and to classical nicotinic antagonists (Bertrand et al., 1990) and for their singlechannel properties (Ballivet et al., 1988; Papke et al., 1989a,b). Assuming that nAChRs in the CNS are composed of $\alpha$ - and $\beta$-subunits, each from a single class, we can make suggestions about the composition of $\mathrm{nAChRs}$ in the IPN and in the MHB. One must keep in mind, however, that neuronal $\mathrm{nAChRs}$ are expected to be pentameric structures, and differences in the stoichiometry, for a given set of $\alpha$ - and $\beta$-subunits, can give rise to differences in functional properties of the receptors (see, e.g., Papke et al., 1989a). In the IPN, $\alpha_{2}^{-}, \alpha_{3}^{-}, \alpha_{4^{-}}$, and $\beta_{2}$-subunits can form functional nAChRs. The combinations $\alpha_{3} \beta_{2}$ and $\alpha_{4} \beta_{2}$ are sensitive to NBT (though to a lesser extent; Luetje et al., 1990). Thus, nAChRs found on IPN neuronal soma could be made up of $\alpha_{2}$ - and $\beta_{2}$-subunits because the $\alpha_{2} \beta_{2}$ combination is insensitive to NBT (Wada et al., 1988; Luetje et al., 1990) and because the single-channel conductance of this nAChR (35 pS; Papke et al., 1989a) is analogous to the single-channel conductance of postsynaptic IPN nAChRs. In the MHB, paired combinations of $\alpha_{3^{-}}, \alpha_{4^{-}}, \beta_{2^{-}}$, and $\beta_{4^{-}}$subunits can form functional nAChRs. In contrast to the combination $\alpha_{3} \beta_{2}, \alpha_{3} \beta_{4}$ is not sensitive to NBT (Duvoisin et al., 1989; Luetje et al., 1990). MHB somatic receptors could thus be composed of $\alpha_{3}$ - and $\beta_{4^{-}}$ subunits, though data concerning agonists and classical antagonists are lacking and though the value of single-channel conductance (Papke et al., 1989b) does not match our data. A high level of ${ }^{125}$ I-NBT binding has been recently demonstrated in the MHB (Schulz et al., 1991), suggesting that some MHB nAChRs could be sensitive to NBT, at variance with somatic and axonal nAChRs, and could thus be composed of $\alpha_{3}$ - and $\beta_{2}$-subunits.

These observations raise the possibility that distinct types of nAChRs can coexist at the level of a single neuron and be differentially targeted either to the soma, to the dendrites, or to axon terminals. The MHB can serve as a model to address this last issue. Because at least five distinct $\mathrm{nAChR}$ genes are expressed in this nucleus, it is reasonable to expect that several nAChR subtypes will coexist in MHB neurons. Furthermore, there are anatonomical (Clarke et al., 1986) and physiological (Brown et al., 1983, 1984; McCormick and Prince, 1987a; Mulle and Changeux, 1990) evidence for the existence of $n A C h R s$ on MHB neurons both at the level of dendrites or soma and at the level of axonal afferents to the IPN. As mentioned above, some $\mathrm{nAChRs}$ in the MHB, probably located at the level of dendrites and not detected under our experimental conditions, could be sensitive to NBT. If demonstrated at a physiological level, this property could provide a tool to discriminate between dendritic and axonal nAChRs in MHB neurons. We show that nAChRs located at the somatic level of MHB neurons and those located on the terminals of MHB axons projecting to the IPN do not differ significantly in their relative sensitivity to several agonists 
and antagonists, but only display a marked difference ( $\times 200$-fold) in their sensitivity to mecamylamine, an antagonist that does not act in a voltage-dependent manner on MHB neurons. However, we cannot draw conclusions as to the difference between nAChRs located on the cell bodies and on the axon terminals of $\mathrm{MHb}$ neurons. This demonstration would require additional approaches, for instance, the use of specific antibodies.

In summary, our results point to the functional diversity of $\mathrm{nAChRs}$ in the rat CNS. This feature is shared with other ligandgated channcls such as GABA, glycinc, and glutamatc rcceptors (for review, see Betz, 1990; Galzi et al., 1991). Diversity could be important for subserving different synaptic functions due to differences in the functional properties of receptors, for example, sensitivity to agonist, rate of desensitization, and $I / V$ relationship. Most of all, as demonstrated for $\mathrm{GABA}_{\mathrm{A}}$ receptors (Pritchett et al., 1989; Lüddens et al., 1990), receptors of a given class can differ in their properties of regulation by allosteric effectors, an important factor in the control of synapse efficacy (Changeux and Heidmann, 1987). Alternatively, subtype heterogeneity could play a role in the differential expression of receptors in terms of development and regional distribution, or in the differential targeting of receptors to various regions of the neuron.

\section{References}

Adams PR (1980) The permeability of end-plate channels to monovalent and divalent metal cations. J Gen Physiol 75:493-510.

Aracava Y, Deshpande S, Swanson K, Rapoport A, Wonnacott S, Lunt $G$, Albuquerque E (1987) Nicotine acetylcholine receptors in cultured neurons from the hippocampus and brain stem of the rat characterized by single channel recordings. FEBS Lett 222:63-70.

Ballivet M, NefP, Couturier S, Rungger D, Bader R, Bertrand D, Cooper E (1988) Electrophysiology of a chick neuronal ACh receptor expressed in Xenopus oocyte after cDN $\Lambda$ injection. Neuron 1:847-852.

Bertrand D, Ballivet M, Rungger D (1990) Activation and blocking of neuronal acetylcholine receptor reconstituted in Xenopus oocytes. Proc Natl Acad Sci USA 87:1993-1997.

Betz H (1990) Ligand-gated ion channels in the brain: the amino acid receptor superfamily. Neuron 5:383-392.

Boulter J, O'Shea-Greenfield A, Duvoisin R, Connoly J, Wada E, Jensen A, Gardner P, Ballivet M, Deneris E, McKinnon D, Heineman S, Patrick J (1990) $\alpha_{3}, \alpha_{5}$ and $\beta_{4}$ : three members of the rat neuronal acetylcholine receptor-related gene family form a gene cluster. J Biol Chem 265:4472-4482.

Brown DA, Docherty RJ, Halliwell J (1983) Chemical transmission in the rat interpeduncular nucleus in vitro. J Physiol (Lond) 341:655670.

Brown DA, Docherty RJ, Halliwell J (1984) The action of cholinomimetic substances on impulse conduction in the habenulo-interpeduncular pathway of the rat in vitro. J Physiol (Lond) 353:101-109.

Changeux J-P, Heidmann T (1987) Allosteric receptors and molecular models of learning. In: Synaptic function (Edelmann G, Gall WE, Cowan WM, eds), pp 549-601. New York: Wiley.

Clarke P, Hommer DW, Pert A, Skirboll LR (1985) Electrophysiological actions of nicotine on substantia nigra single units. Br J Pharmacol 8:827-835.

Clarke P, Schwartz RD, Paul SM, Pert CB, Pert A (1986) [ $\left.{ }^{3} \mathrm{H}\right]$ nicotine and $\left[{ }^{125} \mathrm{I}\right] \alpha$ bungarotoxin-labeled nicotinic receptors in the interpeduncular nucleus of rats. Effects of habenular deafferentation. J Comp Neurol 251:407-413.

Couturier S, Bertrand D, Matter J-M, Hernandez M-C, Bertrand S, Millar N, Valera S, Barkas T, Ballivet M (1990a) The developmentally regulated chick neuronal nicotinic acetylcholine receptor subunit assembles into a homo-oligomeric channel blocked by $\alpha$-bungarotoxin. Neuron 5:847-856.

Couturier S, Erkman L, Valera S, Rungger D, Bertrand S, Boulter J, Ballivet M, Bertrand D (1990b) $\alpha_{5}, \alpha_{3}$ and non- $\alpha_{3}$ : three clustered avian genes encoding neuronal nicotinic receptor-related subunits. $\mathbf{J}$ Biol Chem 265:17560-17567.
De la Garza R, McGuire TJ, Freedman R, Hoffer BJ (1987) Selective antagonism of nicotine actions in the rat cerebellum with $\alpha$-bungarotoxin. Neuroscience 23:887-891.

Deneris ES, Connoly J, Boulter J, Wada E, Wada K, Swanson L, Patrick J, Heinemann $S$ (1988) Primary structure and expression of $\beta_{2}$ : a novel subunit of neuronal nicotinic acetylcholine receptors. Neuron $1: 45-54$.

Deneris ES, Boulter J, Swanson L, Patrick J, Heinemann S (1989) $\beta_{3}$ : a new member of acetylcholine receptor gene family is expressed in the brain. J Biol Chem 264:6268-6272.

Deutch AY, Holliday J, Roth HR, Chun LLY, Hawrot E (1987) Immunocytochemical localization of a neuronal acetylcholine receptor in the mammalian brain. Proc Natl Acad Sci USA 84:8697-8701.

Duvoisin R, Deneris ES, Boulter J, Swanson L, Patrick J, Heinemann $S$ (1989) The functional diversity of the neuronal nicotinic acetylcholine receptors is increased by a novel subunit: $\beta_{4}$. Neuron $3: 487-$ 496.

Egan T, North RA (1986) Action of ACh and nicotine on rat locus coeruleus neurons in vitro. Neuroscience 19:565-571.

Fenwick EM, Marty A, Neher E (1982) A patch-clamp study of bovine chromaffin cells and their sensitivity to ACh. J Physiol (Lond) 331: 577-597.

Galzi J-L, Revah F, Bessis A, Changeux J-P (1991) Functional architecture of the nicotinic acetylcholine receptor: from the electric organ to brain. Annu Rev Pharmacol 31:37-72.

Hamill GS, Lenn NJ (1984) The subnuclear organization of the rat interpeduncular nucleus: a light and electron microscopic study. J Comp Neurol 222:396-408.

Hirano T, Kidokoro Y, Ohmori H (1987) Acetylcholine dose-response relation and the effect of cesium ions in the rat adrenal chromaffin cells under voltage-clamp. Pfluegers Arch 408:401-407.

Ifune CK, Steinbach JH (1990) Rectification of acetylcholine elicited currents in PC12 pheochromocytoma cells. Proc Natl Acad Sci USA 87:4794-4798.

Kay AR, Wong RKS (1986) Isolation of neurons suitable for patchclamping from adult mammalian central nervous system. J Neurosci Methods 16:227-238.

Lindstrom J, Schoepfer R, Whiting P (1987) Molecular studies of the neuronal nicotinic acetylcholine receptor family. Mol Neurobiol 1: 281-337.

Lipton SA, Aizenmann E, Loring R (1987) Neural nicotinic responses in solitary mammalian retinal ganglion cells. Pfluegers Arch 410:3743.

London ED, Connoly J, Szikszay M, Wamsley JK, Dam M (1988) Effects of nicotine on local cerebral glucose utilization in the rat. J Neurosci 8:3920-3928.

Lüddens H, Pritchett DB, Köhler M, Killisch I, Keinänen K, Monyer H, Sprenger R, Seeburg P (1990) A cerebellar GABA-A receptor selective for a behavioural alcohol antagonist. Nature 346:648-651.

Luetje CW, Wada K, Rogers S, Abramson SN, Tsuji K, Heinemann S, Patrick J (1990) Neurotoxins distinguish between different neuronal nicotinic acetylcholine receptor subunit combinations. J Neurochem 55:632-640.

Mathie $\Lambda$, Colquhoun D, Cull-Candy SG (1990) Rectification of currents activated by nicotinic acetylcholine receptors in rat sympathetic ganglion neurones. J Physiol (Lond) 427:625-655.

McCormick DA, Prince DA (1987a) Acetylcholine causes rapid nicotinic excitation in the rat medial habenular nucleus of the guinea pig in vitro. J Neurosci 7:742-752.

McCormick DA, Prince DA (1987b) Actions of acetylcholine in the guinea pig and cat medial and lateral geniculate nuclei in vitro. J Physiol (Lond) 392:147-165.

Morley B (1986) The interpeduncular nucleus. Int Rev Neurobiol 28: 157-182.

Mulle C, Changeux J-P (1990) A novel type of nicotinic receptor in the rat central nervous system characterized by patch-clamp techniques. J Neurosci 10:169-175.

Nef P, Oneyser C, Alliod C, Couturier S, Ballivet M (1988) Genes expressed in the brain define three distinct nicotinic acetylcholine receptors. EMBO J 7:595-601.

Papke R, Boulter J, Patrick J, Heinemann S (1989a) Single-channel currents of rat neuronal nicotinic acetylcholine receptors expressed in Xenopus oocytes. Neuron 3:589-596.

Papke R, Duvoisin R, Boulter J, Heinemannn S (1989b) The possible importance of the neuronal nicotinic subunit $\beta_{4}$ to the kinetic prop- 
erties of the adrenal chromaffin cell AChR. Soc Neurosci Abstr 15: 333.

Pritchett DB, Lüddens H, Seeburg P (1989) Type I and type II GABA $A^{-}$ benzodiazepine receptors produced in transfected cells. Science 245 : 1306-1308.

Schulz DW, Zigmond RE (1989) Neuronal bungarotoxin blocks the nicotinic stimulation of endogenous dopamine release from rat striatum. Neurosci Lett 98:310-316.

Schulz DW, Loring RH, Aizenman E, Zigmond RE (1991) Autoradiographic localization of putative nicotinic receptors in the rat brain using ${ }^{125}$ I-neuronal bungarotoxin. J Neurosci 11:287-297.

Sorenson EM, Chiappinelli VA (1990) Intracellular recording in avian brain of a nicotinic response that is insensitive to kappa-bungarotoxin. Neuron 5:307-315.

Swanson L, Simmons D, Whiting P, Lindstrom J (1987) Immunohistochemical localization of neuronal nicotinic receptors in the rodent nervous system. J Neurosci 7:3334-3342.

Vidal C, Changeux J-P (1989) Pharmacological profile of nicotinic acetylcholine receptors in the rat prefrontal cortex: an electrophysiological study in a slice preparation. Neuroscience 29:261-270.

Wada K, Ballivet M, Boulter J, Connoly J, Wada E, Deneris ES, Swanson L, Heinemann S, Patrick J (1988) Functional expression of a new pharmacological subtype of brain nicotinic receptor. Science 240:330334. 